\title{
Methods of vacuum consolidation and their deformation analyses
}

1 Jinchun Chai DEng Professor, Saga University, Saga, Japan

2 John P. Carter PhD

Emeritus Professor, The University of Newcastle, Newcastle, NSW, Australia
3 Martin D. Liu PhD

Senior Lecturer, The University of Wollongong, Wollongong, NSW Australia
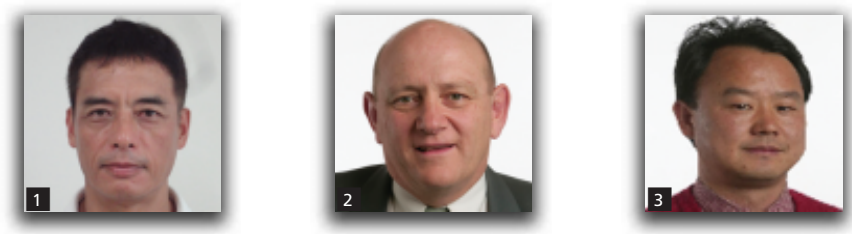

Two methods, namely the air-tight sheet method and the vacuum-drain method (sheetless), are generally used to conduct vacuum consolidation in the field. The advantages and disadvantages of both methods and the techniques for preventing vacuum leakage through a middle sand layer in a deposit, as well as the method for maintaining vacuum pressure when large settlement occurs, have been described. Vacuum pressure is an isotropic consolidation pressure applied to a soil deposit, and the deformation induced is different from that induced by a surcharge (e.g. the weight of an embankment). Two typical case histories in Japan are presented and deformation analyses were conducted. In one case history the vacuum-drain method was used with vacuum pressure alone, and in the other a combination of embankment loading and vacuum pressure was applied employing the air-tight sheet method. It is shown that under vacuum pressure loading, the ground deformation (settlement and lateral displacement) can be calculated reliably using a method proposed previously. For the case involving a combination of vacuum pressure and embankment load, the settlements under the embankment centreline can be estimated reasonably assuming one-dimensional deformation conditions.

\section{Notation}

$C_{\mathrm{c}} \quad$ compression index

$c^{\prime} \quad$ effective stress cohesion (M/LT ${ }^{2}$ )

$c_{\mathrm{h}} \quad$ coefficient of consolidation in horizontal direction $\left(\mathrm{L}^{2} / \mathrm{T}\right)$

$c_{\mathrm{V}} \quad$ coefficient of consolidation in vertical direction $\left(\mathrm{L}^{2} / \mathrm{T}\right)$

$D_{\mathrm{e}} \quad$ diameter of a prefabricated vertical drain (PVD) unit cell (L)

$d_{\mathrm{s}} \quad$ diameter of smear zone (L)

$d_{\mathrm{w}} \quad$ diameter of vertical drain (L)

$e_{0} \quad$ initial void ratio

$k \quad$ hydraulic conductivity $(\mathrm{L} / \mathrm{T})$

$K_{0} \quad$ at-rest earth pressure coefficient

$K_{\mathrm{a}} \quad$ active earth pressure coefficient

$K_{\mathrm{a} 0} \quad$ earth pressure coefficient for the zone subjected to vacuum consolidation

$k_{\mathrm{h}} \quad$ hydraulic conductivity in horizontal direction (L/T)

$k_{\mathrm{s}} \quad$ hydraulic conductivity of smear zone (L/T)

$p_{\mathrm{c}} \quad$ maximum consolidation pressure $\left(\mathrm{M} / \mathrm{LT}^{2}\right)$

$p_{i} \quad$ load at $i$ step $\left(\mathrm{M} / \mathrm{LT}^{2}\right)$ $p_{j} \quad$ load at $j$ step $\left(\mathrm{M} / \mathrm{LT}^{2}\right)$

$q_{\mathrm{w}} \quad$ discharge capacity of prefabricated vertical drain $\left(\mathrm{L}^{3} / \mathrm{T}^{1}\right)$

$s_{\mathrm{u}} \quad$ undrained shear strength $\left(\mathrm{M} / \mathrm{LT}^{2}\right)$

$t_{i} \quad$ time at $i$ step (T)

$t_{j 0} \quad$ an imaginary time (T)

$T_{j 0} \quad$ an imaginary time factor

$U_{i} \quad$ degree of consolidation at $i$ step

$U_{j} \quad$ degree of consolidation at $j$ step

$\alpha \quad$ a multiple factor (less than or equal to $1 \cdot 0$ )

$\alpha_{\min }$ minimum value of $\alpha$ factor

$\beta \quad$ a parameter required to determine the earth pressure coefficient for the zone subjected to vacuum consolidation

$\gamma_{\mathrm{t}} \quad$ total unit weight of soil $\left(\mathrm{M} / \mathrm{L}^{2} \mathrm{~T}^{2}\right)$

$\Delta p_{j} \quad$ load increment at $j$ step (M/LT $\left.{ }^{2}\right)$

$\Delta t \quad$ time increment $(\mathrm{T})$

$\Delta \sigma_{\mathrm{v}}^{\prime} \quad$ vertical effective stress increment (M/LT $\left.{ }^{2}\right)$

$\sigma_{g}^{\prime} \quad$ vertical effective stress due to the gravitational force $\left(\mathrm{M} / \mathrm{LT}^{2}\right)$ 
$\sigma_{\mathrm{v} 0}^{\prime} \quad$ initial effective vertical stress (M/LT $\left.{ }^{2}\right)$

$\phi^{\prime} \quad$ Effective stress friction angle $\left({ }^{\circ}\right)$

\section{Introduction}

Preloading a soft clayey deposit using vacuum pressure or the combination of vacuum pressure and surcharge load (embankment fill) is now an effective and economic soft ground improvement method (e.g. Bergado et al., 1998; Chai et al., 2008; Indraratna et al., 2011). Although the principle of vacuum consolidation was proposed as early as the 1950s (Kjellman, 1952), its regular use in engineering applications did not commence until much later in the 1980s. This change in usage occurred largely as a result of developments in air-sealing techniques and in available materials.

Vacuum consolidation has been used for: (a) consolidating soft clayey deposits for road, airport and harbor construction (e.g. Chai et al., 2008; Indraratna et al., 2011; Tang and Shang, 2000); (b) improving under-consolidated, often reclaimed soft soil deposits (e.g. Nakaoka et al., 2005); and (c) reducing the volume of dredged clayey soils (Miyakoshi et al., 2007a). In the present study the methods adopted for field vacuum consolidation and existing methods for the analysis of the ground deformations induced by vacuum consolidation, and the combination of vacuum pressure and embankment loading, are discussed and illustrated using two case histories.

\section{Field methods for vacuum consolidation}

In practice, there are two main methods used to conduct vacuum consolidation in the field, namely the air-tight sheet method and the vacuum-drain method (Chai and Carter, 2011). In order to accelerate the soil consolidation process, vacuum consolidation is normally combined with prior installation of prefabricated vertical drains (PVDs) into the ground.

\subsection{Air-tight sheet method}

This method involves placing an air-tight sheet on the ground surface in the first instance and sealing the periphery of the sheet by embedding it in the ground. Air and water in the soil below the sheet are then sucked from the ground by a vacuum pump (Figure 1).

\subsection{Vacuum-drain method}

This method uses a surface or subsurface clayey layer as an airsealing layer and involves application of the vacuum pressure directly to PVDs with specially made caps. This kind of PVD is usually referred to as a capped PVD or simply CPVD (Chai et al., 2008). As illustrated schematically in Figure 2, the cap provides an interface between the rectangular-shaped PVD and the drainage hose or pipe, which is usually circular in crosssection. Each CPVD is connected to a geosynthetic pipe placed on the ground surface, which in turn is connected to a vacuum pump. This technique is usually denoted as the 'vacuum-drain method'. In practice, the thickness of the surface or subsurface sealing layer is normally about 1.0 to $2.0 \mathrm{~m}$.

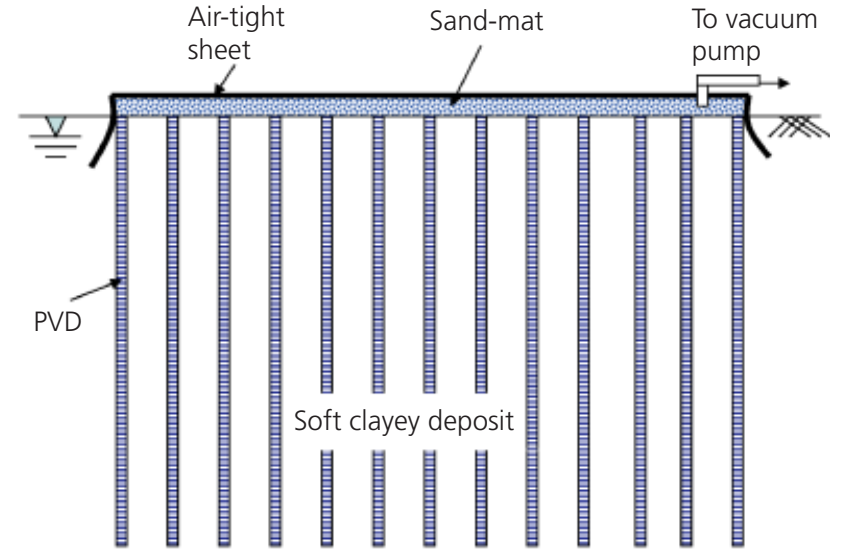

Figure 1. Illustration of original vacuum consolidation technique

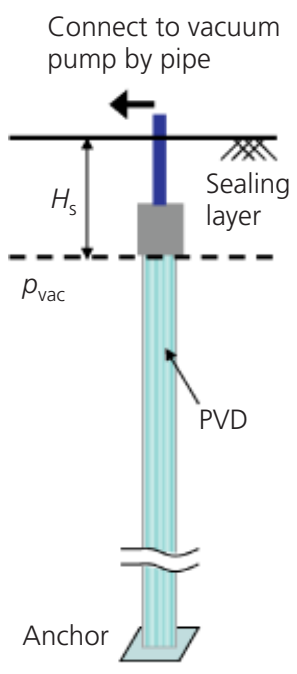

(a)

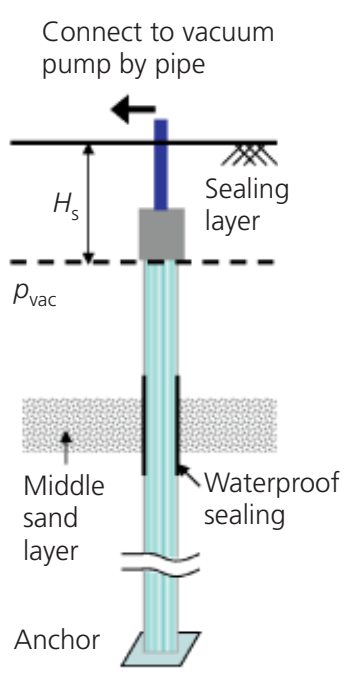

(b)
Figure 2. Vacuum consolidation with CPVDs (after Chai et al., 2008): (a) without a sand layer (b) with a sand layer

\subsection{Advantages of each method}

Which of the above two methods is better? The effectiveness of all vacuum consolidation methods depends on air-tightness. There are situations in which both methods can be applied, and there are situations in which one of the methods may be more efficient and some examples are provided here.

- Consolidating a soft surface layer. For this kind of situation the air-tight sheet method may be better, as a higher value of the effective vacuum pressure in the soil is normally attainable with this method.

- Presence of a layer with high air/water permeability at the ground surface. In this case, if the air-tight sheet method is adopted, the sheet must be embedded below this permeable layer, or an air/water cut-off wall penetrating through this layer and into the underlying lower permeability layer must 
be constructed around the perimeter of the preloading area. In cases where the vacuum-drain method is used, the caps of the CPVDs can be installed below the high air/water permeability layer without additional cost, and indeed the method may have a distinct advantage for these conditions.

- Combining vacuum pressure with embankment load. In the case of the air-tight sheet method, after placing embankment fill, any damage to the sheet cannot be identified and repaired. Consequently, the effect of vacuum pressure will be reduced in cases in which the sheet has sustained damage during construction (Bergado et al., 1998). In such situations the vacuum-drain method will be less vulnerable to the effects of this type of damage. Furthermore, in the field, a valve is normally installed on the pipe which is connected to a row of CPVDs. If there is vacuum leakage, the leaking row can be identified easily by closing the valve of each row in turn and monitoring the change of the measured vacuum pressures. Once identified, the valve of the leaking row can be closed permanently and the remaining rows can still work effectively.

- Consolidating a soft clayey deposit under water. There are situations in which a soft soil layer lying entirely beneath the water table needs to be consolidated by applying vacuum pressure (Miyakoshi et al., 2007a). Usually it is not convenient to place an air-tight sheet below the water level; hence in this situation the vacuum-drain method is preferable.

\subsection{Preventing vacuum loss through an intermediate sand layer}

There are cases in which sandy layer(s) may be sandwiched within a soft clay deposit. If a vacuum pressure is applied to this kind of deposit, it may be transmitted by way of the sand layer to surrounding areas for which this type of ground treatment was unintended. This phenomenon will not only reduce the effectiveness of the vacuum consolidation in the area of intended treatment, but it could also result in unintended damage to infrastructure in the area nearby. To avoid vacuum pressure loss through an intermediate sand layer, a sealing sheet should be placed over the filter of that section of PVD passing through the sandy layer. This sealing sheet is usually attached to the filter using some appropriate glue (Figure 2(b)).

To use the technique shown in Figure 2(b) effectively, an intelligent construction system is also needed. One method that has been successfully employed involves placing a piezocone on the tip of the mandrel used to install the CPVDs (Nomura et al., 2007). The piezocone readings obtained during any given CPVD installation can then be used to infer the locations of any sealing sheets that might be required on the adjacent CPVDs subsequently installed.

\subsection{Maintaining vacuum pressure for cases of large settlement}

In general, in situations in which large settlements occur, it is reasonable to expect that if the vacuum pump is located and maintained at the elevation of the original ground surface, the magnitude of the vacuum pressure applied to the area of improvement will reduce. Figure 3(a) illustrates the case of the combination of an embankment loading and a vacuum pressure. Theoretically, if the settlement is more than $10 \mathrm{~m}$, effectively no vacuum pressure can be applied to the ground. However, if the vacuum pump is also permitted to settle (Figure 3(b)), the reduction of the vacuum pressure due to larger settlement can be avoided. The layout depicted in Figure 3(b) for the air-tight sheet method has been named the air-water separation system (Imai, 2005). The general advantage of this type of system is that by pumping out the air from a pump on the original ground surface, a smaller capacity pump (embedded under the sealing sheet) can serve the purpose of pumping out the water and maintaining a higher vacuum pressure under the sheet. As a result, the efficiency of the pumping system can be increased.

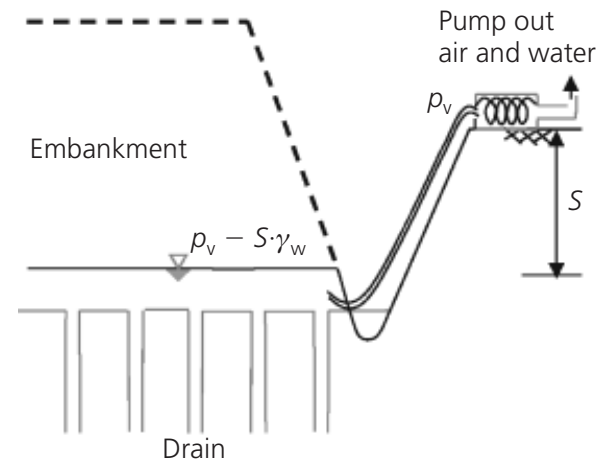

(a)

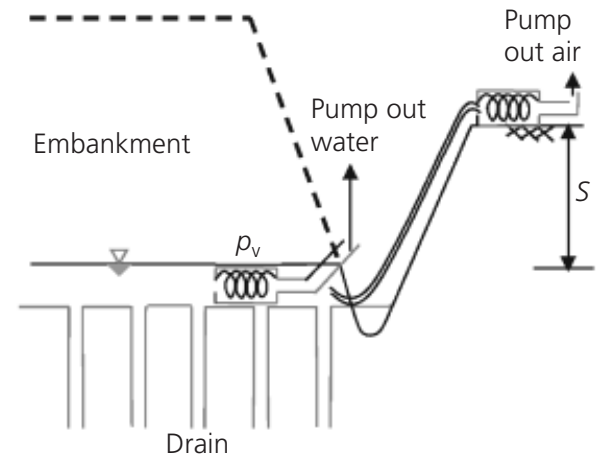

(b)

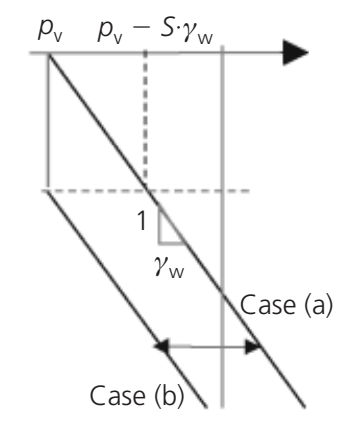

(c)

Figure 3. Illustration of air-water separation system and its advantages: (a) pump out air and water together; (b) pump out air and water separately; (c) vacuum pressure distribution 


\section{Deformation analysis}

In principle, finite-element analysis can predict the ground deformations induced by a vacuum pressure and/or the combination of a vacuum pressure and a surcharge load. However, the accuracy of these predictions depends on the constitutive models used to represent the stress-strain behaviour of the soils in question. In many practical cases, there is often not enough information to reliably define the parameter values of sophisticated soil models. Two practical easy-to-use methods have been proposed for calculating the settlement and lateral displacement of a soil deposit induced by vacuum pressure (Chai et al., 2005; Imai, 2005). Imai's method is based on elasticity theory, and the method proposed by Chai et al. considers the elasto-plastic deformation behaviour of a deposit, and as such is considered more relevant for clay soils.

Vacuum pressure is an isotropic consolidation stress increment. For a normally consolidated clayey soil the deformation resulting from the application of a vacuum will be elasto-plastic, and for the plastic component of that deformation the directions and the magnitudes of deformation are directly related to the directions and the magnitudes of the initial effective stresses that exist in the soil mass. This implies that even under an isotropic consolidation stress increment the soil may not deform isotropically; that is, the principal strain increments may not be equal in magnitude.

However, deformation induced by a vacuum pressure is different from that induced by a surcharge load. A vacuum pressure will induce settlement, and at the same time has a tendency to induce inward lateral displacement of the ground. Consequently, for vacuum consolidation, if inward lateral displacement occurs, the settlement induced by a vacuum pressure will normally be less than that induced by a surcharge load of the same magnitude. Chai et al. (2005) proposed that the settlement induced by a vacuum pressure may be calculated as the value of the settlement predicted by onedimensional consolidation theory multiplied by a factor, $\alpha$, which is a function of initial effective stress condition in a soil mass and a (constant) parameter, $\alpha_{\min }$, which is equal to or less than unity. Recognising the possibility of non-isotropic deformation in a normally consolidated deposit, Chai et al. proposed that $\alpha_{\min }=0 \cdot 8$ for triaxial deformation conditions (i.e. in practice an improvement area that is either circular or square in plan) and 0.85 for plane strain conditions (i.e. a strip improved area). However, it should be noted that if the response of the soil is isotropic then the values of $\alpha_{\min }$ would be 0.33 for triaxial conditions and 0.5 for plane strain conditions.

For an under-consolidated deposit subjected to a vacuum pressure there will be a tendency for the resulting deformation to be closer to isotropic (Chai et al., 2008, 2010). In addition, it is considered that when applying a vacuum pressure to a soil mass in a slurry state, the soil will deform in a manner close to isotropic. Based on these observations, it can be easily reasoned that for an underconsolidated deposit, the value of $\alpha_{\min }$ should be between the values for the normally consolidated state and the isotropic deformation state. In this study a simple variation of $\alpha_{\min }$ with vertical effective stress is proposed. Designating the initial vertical effective stress in an under-consolidated deposit as $\sigma_{\mathrm{v} 0}^{\prime}$, and the vertical effective stress due to the gravitational force (corresponding to a normally consolidated state) as $\sigma_{\mathrm{vg}}^{\prime}$, the value of $\alpha_{\min }$ for an under-consolidated deposit can be calculated as follows

$$
\text { 1. } \alpha_{\min }=0.33+0.47 \cdot \sigma_{\mathrm{v} 0}^{\prime} / \sigma_{\mathrm{vg}}^{\prime}(\text { triaxial condition })
$$

2. $\alpha_{\min }=0.5+0.35 \cdot \sigma_{\mathrm{v} 0}^{\prime} / \sigma_{\mathrm{vg}}^{\prime}$ (plane strain condition)

\section{Vacuum consolidation at Tokyo Bay}

\subsection{Site history, analytical model and soil parameters}

Two field test sections (A and B) were constructed with the vacuum-drain method in Tokyo Bay, Japan, in order to consolidate the soft clayey deposit located at the sea bed as well as the overlying dredged clayey silt layers (Miyakoshi et al., 2007a, 2007b). Section A had an area of $60 \mathrm{~m} \times 60 \mathrm{~m}$ and section B an area of $61.2 \mathrm{~m} \times 61.2 \mathrm{~m}$, and the two sections were almost adjoining, as shown in Figure 4. The soil profile at this site

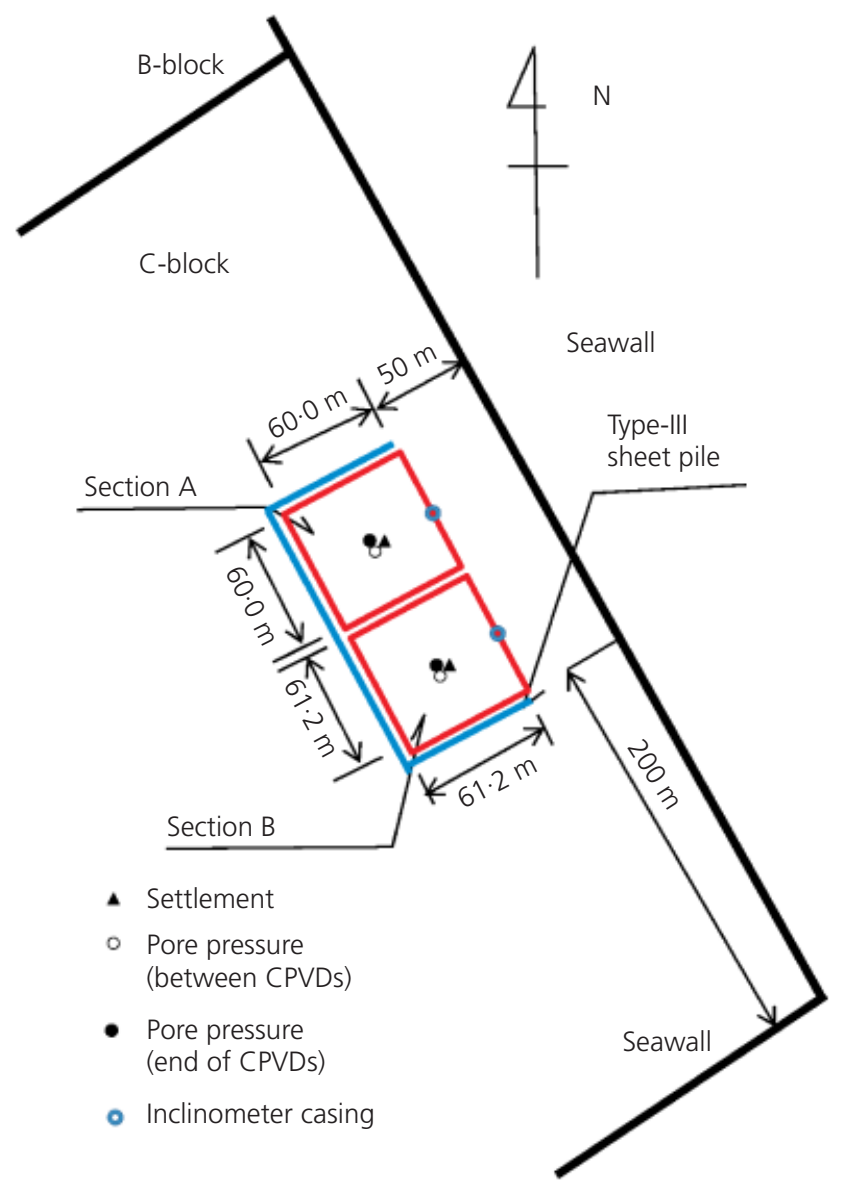

Figure 4. Plan view of test sections and key instrumentation points (after Chai et al., 2010) 
consists of a reclaimed clayey silt layer about $12 \mathrm{~m}$ thick. Below it is a natural clayey deposit about $29 \mathrm{~m}$ thick, which in turn is underlain by a sand layer. The majority of the reclamation was carried out between 2003 and 2005 with a rate of filling of about $3.5 \mathrm{~m} /$ year. The total unit weight $\left(\gamma_{\mathrm{t}}\right)$, the compression index $\left(C_{\mathrm{c}}\right)$ and the maximum consolidation pressure $\left(p_{\mathrm{c}}\right)$ of the deposits before vacuum consolidation are shown in Figure 5. It can be seen that the reclaimed silty layer was close to being normally consolidated but the original clayey deposit was initially in an under-consolidated state with an unconsolidated stress of about $40 \mathrm{kPa}$ (as illustrated in Figure 5).

The CPVDs used at this site had a cross-sectional area of $150 \mathrm{~mm}$ by $3 \mathrm{~mm}$. At section A, the CPVDs had a spacing of $2.0 \mathrm{~m}$, whereas at section $\mathrm{B}$ it was $1.8 \mathrm{~m}$, and in both cases the CPVDs were installed on a square grid pattern. For both sections, the CPVDs were installed to a depth of $30 \mathrm{~m}$ from the ground surface, and the sealing surface layer had a thickness of about $1.0 \mathrm{~m}$. The field installation of CPVDs started at the beginning of January 2006 for section A, and at the beginning of February 2006 for section B, and for the both sections the duration of the installation process was about 1 month. The durations between the end of CPVD installation and just prior to application of the vacuum pressure were about 5 and 4 months for section $\mathrm{A}$ and section $\mathrm{B}$, respectively. Considering half of the period of the CPVD installation as consolidation time, the partial self-weight consolidation periods before application of the vacuum pressure were estimated to be about $165 \mathrm{~d}$ and $135 \mathrm{~d}$ for section A and section B, respectively. From 30 June 2006, a vacuum pressure of -80 to $-90 \mathrm{kPa}$, as measured at the vacuum pump location, was applied and maintained for $204 \mathrm{~d}$. Surface and subsurface settlement gauges, excess pore water pressure gauges, as well as inclinometer casings were installed to monitor the ground response. The key instrumentation points are indicated in Figure 4.

This case was analysed by Chai et al. (2010) using the method proposed by Chai et al. (2005) with constant values of $\alpha_{\min }$. It has been re-analysed in this study using $\alpha_{\min }$ values calculated by Equations 1 and 2. The model adopted in the consolidation analysis and the values of the soil parameters estimated or assumed for each layer are shown in Figure 6. With the vacuumdrain method a vacuum pressure is applied to each CPVD and, for conditions of two-way drainage, the distribution of the vacuum pressure in the ground is approximated by the method proposed by Chai et al. (2010). The degrees of consolidation of the surface and the bottom layers without PVDs were calculated by the method proposed by Ong et al. (2012). The parameters relating to PVD consolidation are: the diameter of the PVDs, $d_{\mathrm{w}}=75 \mathrm{~mm}$; the diameter of the smear zone, $d_{\mathrm{s}}=0.3 \mathrm{~m}$; the discharge capacity of the PVD, $q_{\mathrm{w}}=1.37 \mathrm{~m}^{3} /$ day $\left(500 \mathrm{~m}^{3} /\right.$ year $)$; and the hydraulic conductivity ratio, $k_{\mathrm{h}} / k_{\mathrm{s}}=2\left(k_{\mathrm{h}}\right.$ and $k_{\mathrm{s}}$ are

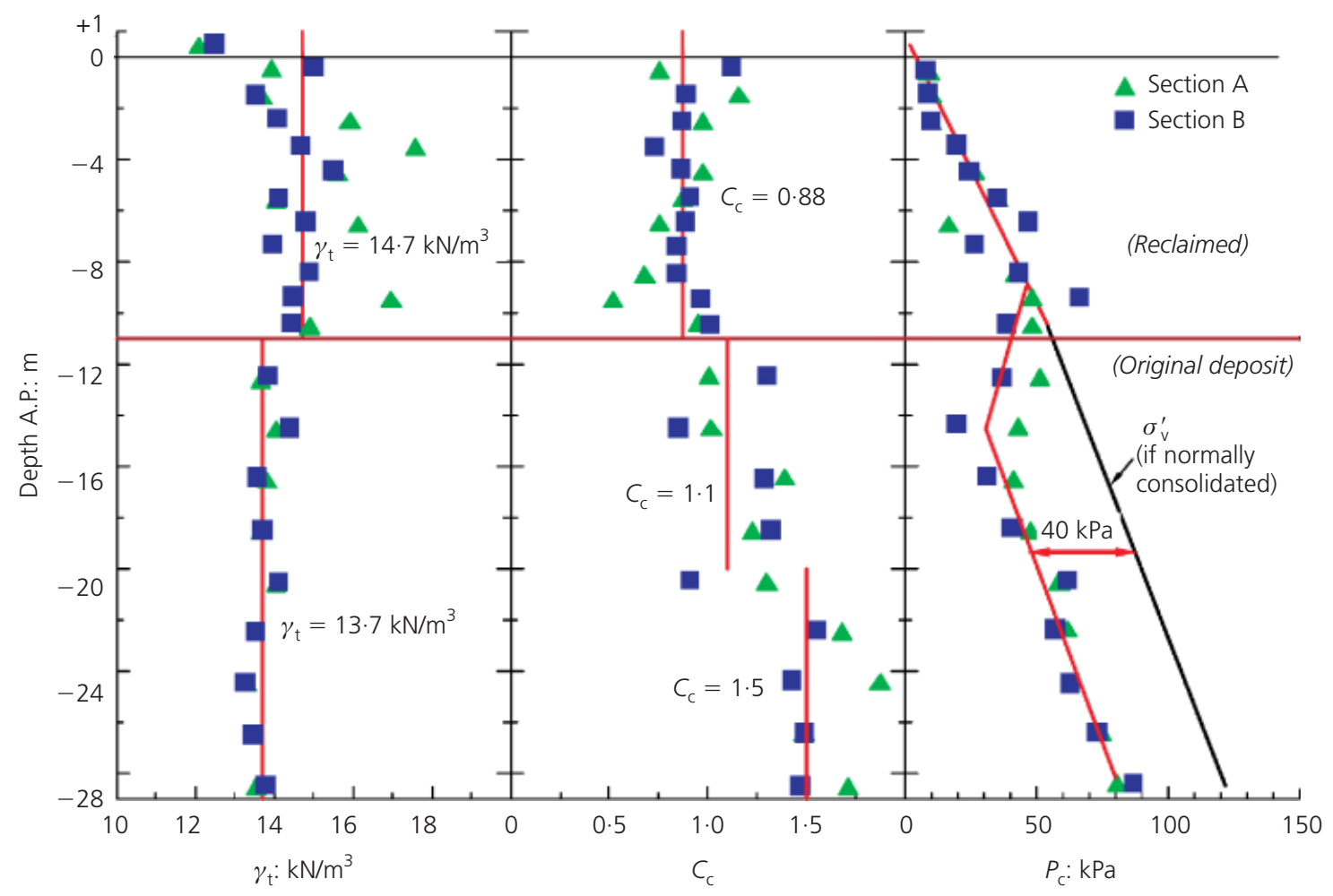

Figure 5. Properties $\gamma_{\mathrm{t}}, C_{\mathrm{c}}$ and $p_{\mathrm{c}}$ of the Tokyo Bay deposit

(measured data from Miyakoshi et al., 2007b - after Chai et al.,

2010) 


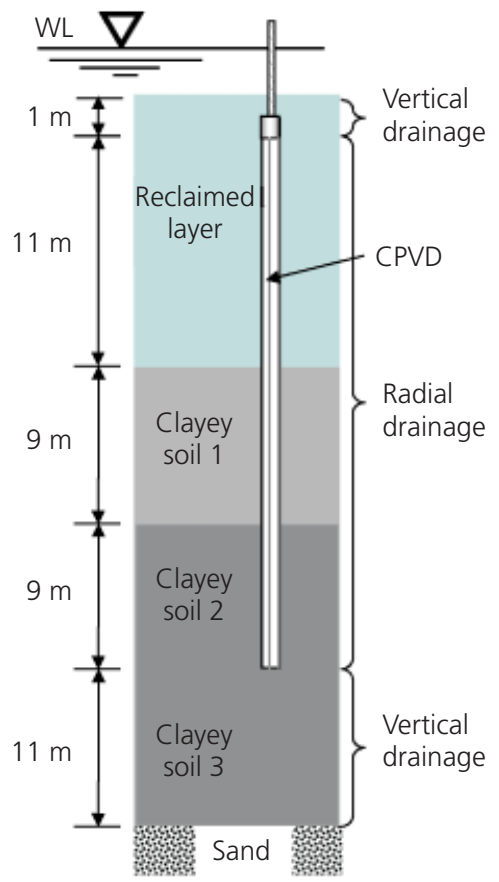

Figure 6. Consolidation analysis model (after Chai et al., 2010)

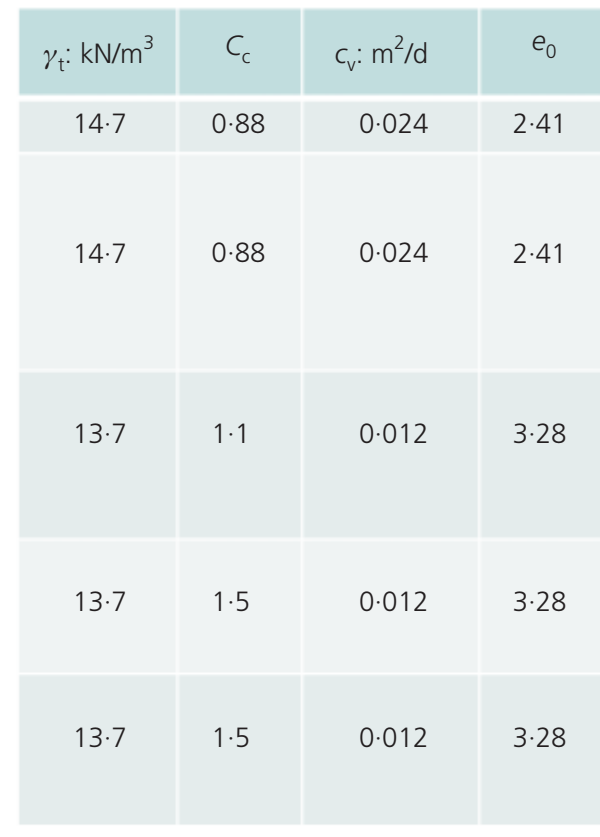

For all layers, $c_{h}=2 c_{v}$ horizontal hydraulic conductivities of the natural soil and the smear zone, respectively).

The consolidation of the soil layer can be divided into two periods, namely, period 1 - after CPVD installation but before vacuum pressure application; and period-2 - during vacuum consolidation. The analyses were also divided accordingly into these two parts.

\subsection{Settlement and lateral displacement}

Based on the field-measured data (Miyakoshi et al., 2007a, $2007 b$ ), it was assumed that the final vacuum pressure at the location of the caps of the CPVDs $\left(p_{\mathrm{v}-\mathrm{t}}\right)$, that is $1.0 \mathrm{~m}$ below the ground surface, was $-70 \mathrm{kPa}$. The value of vacuum pressure at the bottom end of the CPVDs $\left(p_{\mathrm{v}-\mathrm{b}}\right)$ was calculated to be about $-69 \cdot 3 \mathrm{kPa}$ for both sections (Chai et al., 2010). One-dimensional consolidation theory (Terzaghi, 1943) was used to consider the effect of vertical drainage of the natural deposit and Hansbo's (1981) solution (Hansbo, 1981) was adopted for the effect of radial drainage. With the degree of consolidation and therefore the increment of effective stress $\left(\Delta \sigma_{\mathrm{v}}^{\prime}\right)$ known, the compression of each soil layer can be easily computed using the appropriate linear $e-\log \sigma_{\mathrm{v}}^{\prime}$ relationship, where $e$ is the void ratio, and $\sigma_{\mathrm{v}}^{\prime}$ is the vertical effective stress.

Although there was lateral displacement observed after CPVD installation and before vacuum pressure application, it was assumed that the consolidation induced by self-weight was onedimensional and so only the settlement was calculated for this phase. However, both the settlement and the lateral displacement induced by vacuum consolidation were calculated. With the method proposed by Chai et al. (2005), the deformation calculations depend on whether triaxial or plane strain deformation patterns are assumed in the ground. For these specific cases, in the analysis it was assumed that the deformations are the average values obtained after making both the triaxial and plane strain assumptions. The additional parameters adopted for the purpose of calculating the depth of possible tension cracks near the ground surface are: the effective stress friction angle, $\phi^{\prime}=30^{\circ}$, cohesion, $c^{\prime}=5 \mathrm{kPa}$. The half width of the improved area was assumed to be $B=30 \mathrm{~m}$ for section A and $30.6 \mathrm{~m}$ for section $\mathrm{B}$, respectively. Value of $\alpha_{\min }$ was calculated from Equations 1 and 2. The remaining model parameter is $\beta$, which is a parameter required to determine the earth pressure coefficient $\left(K_{\mathrm{a} 0}\right)$ for the zone subjected to vacuum consolidation (Chai et al., 2005). When $\beta=1 \cdot 0, K_{\mathrm{a} 0}=K_{\mathrm{a}}$; and when $\beta=2 / 3, K_{\mathrm{a} 0}=2 K_{\mathrm{a}} / 3+K_{0} / 3$, where $K_{\mathrm{a}}$ is the active earth pressure coefficient and $K_{0}$ is the at-rest earth pressure coefficient. In this study, $\beta=1.0$ was adopted.

The calculated settlements are compared with measured values in Figures 7(a) and (b) for section A and section B respectively. In these figures, 'calculated-1' is from the methods proposed by Chai et al. $(2005,2010)$, and 'calculated-2' is from the modified method; that is, using values of $\alpha_{\min }$ from Equations 1 and 2. It can be seen that calculated-2 is closer to the measured values.

Comparison of the lateral displacement profiles at the edge of the improved area is depicted in Figures 8(a) and (b) for section A and section $\mathrm{B}$, respectively. Although there are still discrepancies between the measured and calculated- 2 profiles, it can be said 


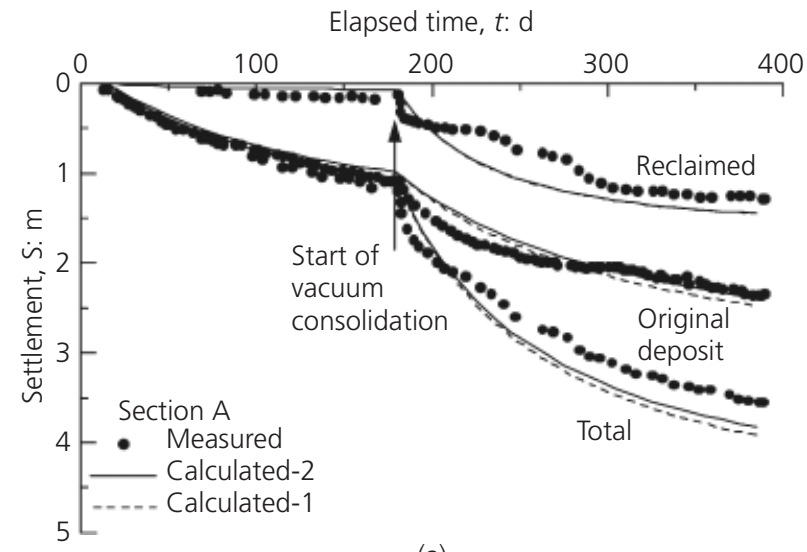

(a)

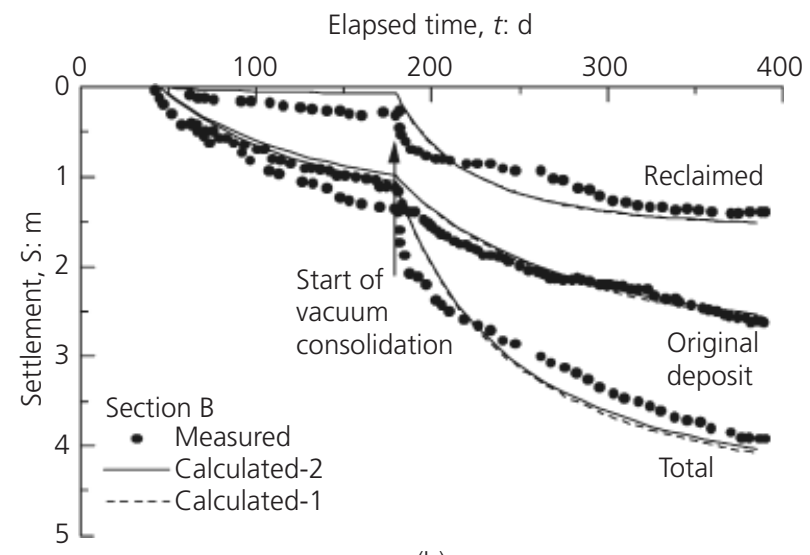

(b)

Figure 7. Settlement plotted against elapsed time (measured data from Miyakoshi et al., 2007a): (a) section A, (b) section B

that calculated-2 is at least fair to good when compared with the measured data, and calculated-2 is closer to the measured data than calculated-1 (Chai et al., 2010).

The results presented in Figures 7 and 8 indicate that the methods proposed by Chai et al. $(2005,2010)$ with the modification proposed in this study for calculating the settlement-time curves and the final lateral displacement profiles, are useful design tools for vacuum consolidation projects.

\section{Vacuum combined with embankment preloading at Mukasa, Fukui Prefecture}

\subsection{Soil profile}

Along the Maizuru-Wakasa expressway in the Mukasa area, Fukui Prefecture, Japan, there is a thick soft soil deposit consisting mainly of peat layers, which have natural water contents of about 100 to $250 \%$. In order to achieve the target elevation of the expressway, embankments at least $10 \mathrm{~m}$ high (and usually considerably thicker to compensate for embankment settlement) had to be built on this deposit. Considering both the construction cost as well as the construction time limits, a method of combining vacuum consolidation with embankment construction was adopted for this project (Yamada et al., 2010).

The soil profile and the cross-section of the embankment are shown in Figure 9. The soft layers above the gravel or bed rock are about $39 \mathrm{~m}$ thick under the centre of the embankment.

\subsection{Construction history}

First, PVDs with a length of about $34 \mathrm{~m}$ arranged in a square pattern at a spacing of $1.2 \mathrm{~m}$ were installed in the ground. The overall width of the improved area was about $68 \mathrm{~m}$. Subsequently, it was considered that under the specified construction schedule, there might be a stability problem of the embankment with the adoption of only PVD improvement, and so it was decided to use vacuum consolidation to assist by increasing the preloading stress and enhancing the stability of the embankment. This required the installation of additional PVDs between those already installed. These additional PVDs were installed to $20 \mathrm{~m}$ depth with a spacing of $1.2 \mathrm{~m}$, also on a square pattern, and horizontal drains were placed on the tops of the newly installed PVDs for conducting vacuum consolidation. The air-tight sheet method was adopted for this project. Surface and subsurface settlement plates, pore pressure gauges, casing for measuring lateral displacement and surface deformation markers were installed, as shown in Figure 9.

Vacuum pressure was applied prior to the embankment construction, and during the whole consolidation period. The vacuum pressure measured under the air-tight sheet was consistently about -80 to $-90 \mathrm{kPa}$. After about 25 days of applying the vacuum pressure, embankment construction commenced with an average filling rate of about $0.08 \mathrm{~m} / \mathrm{d}$ to a final fill thickness of about $24 \mathrm{~m}$. The embankment construction history is shown in Figure 10. About 2.5 months after the completion of the embankment construction, the vacuum pumping was stopped (Yamada et al., 2010). At this site the observed surface settlement was $10.6 \mathrm{~m}$, and the air-water separation system (Imai, 2005) was adopted.

\subsection{Calculated settlement-time curves and comparison with measurements \\ 5.3.1 Soil properties}

Based on the information given by Hirata et al. (2010), the measured or estimated soil properties required for the calculation of consolidation settlements are summarised in Table 1. In this table, the values listed for $e_{0}$ and $C_{\mathrm{c}}$ are measured values. Values of $\gamma_{\mathrm{t}}$ were calculated using the appropriate value of $e_{0}$ and assuming that the soil was saturated and the densities of the soil particles (specific gravity multiplied by the unit weight of water) were $26.0 \mathrm{kN} / \mathrm{m}^{3}$ for the clayey soils and $24.5 \mathrm{kN} / \mathrm{m}^{3}$ for the peat soils. Hirata et al. (2010) reported that the hydraulic conductivity $(k)$ of the clayey soils was about $6 \times 10^{-9} \mathrm{~m} / \mathrm{s}$ and about $10^{-8} \mathrm{~m} / \mathrm{s}$ for the peat soils. Referring to these values of $k$ and the reported values of $C_{\mathrm{c}}$ for the soil layers, and assuming that the coefficient of consolidation in the horizontal direction $\left(c_{\mathrm{h}}\right)$ is twice that in the vertical direction $\left(c_{\mathrm{V}}\right)$, values of $c_{\mathrm{h}}$ and $c_{\mathrm{v}}$ were back-estimated at 


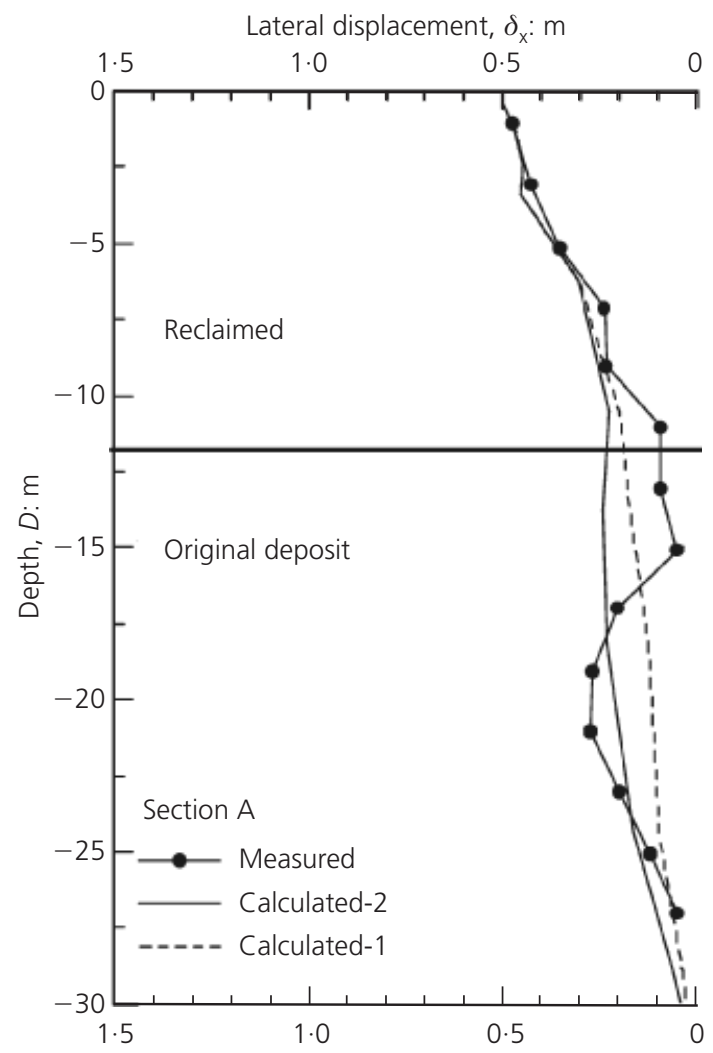

(a)

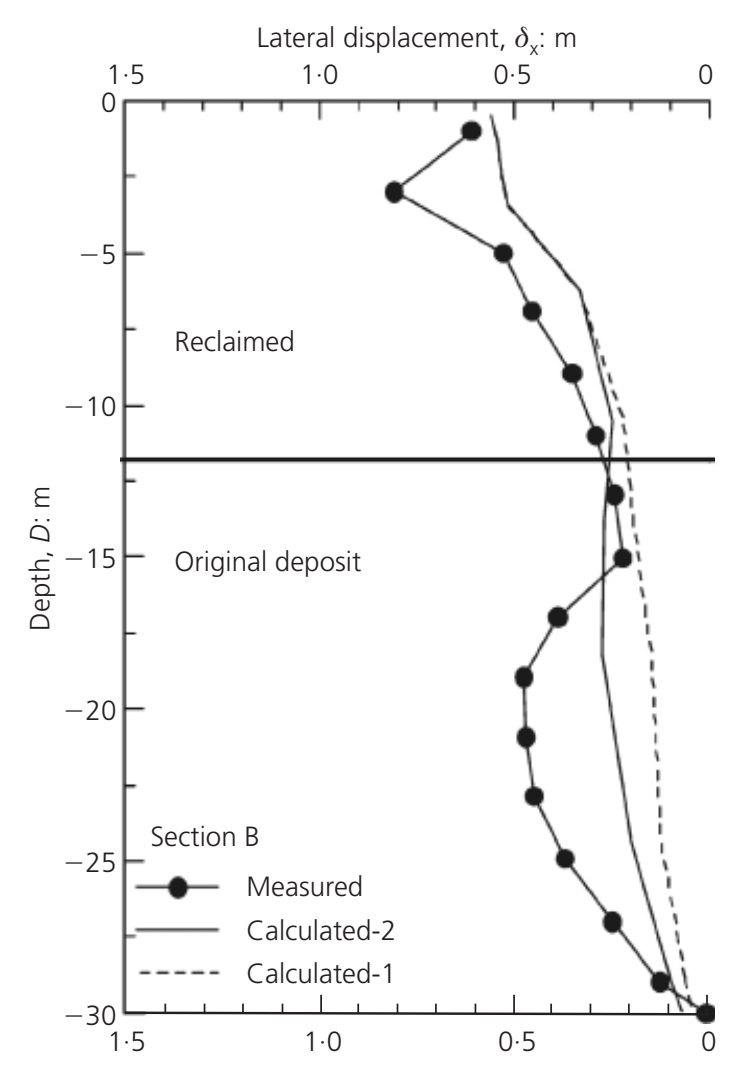

(b)

Figure 8. Comparison of lateral displacement (measured data from Miyakoshi et al., 2007a): (a) section A, (b) section B

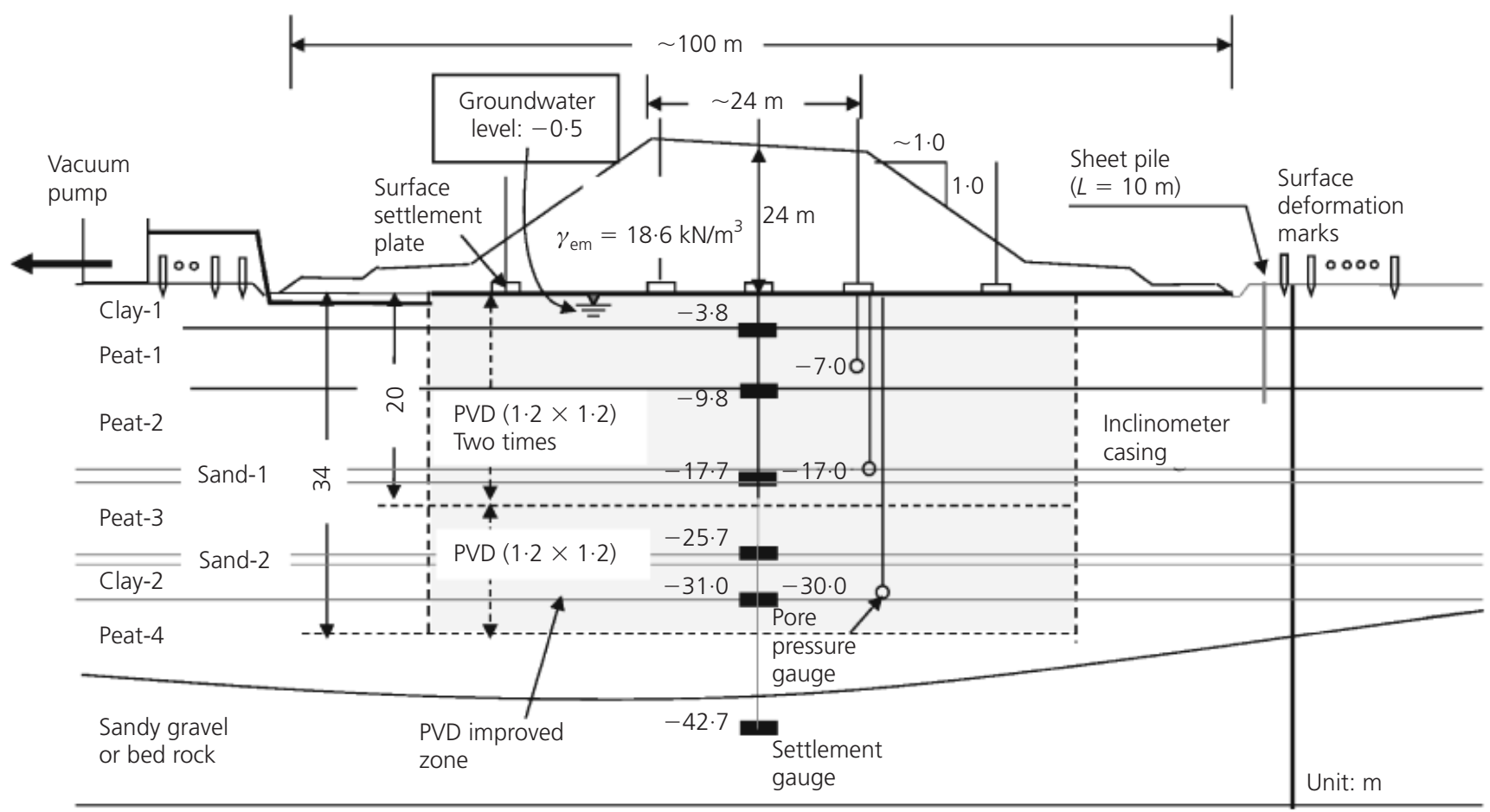

Figure 9. Soil profile and the cross-section of the embankment 


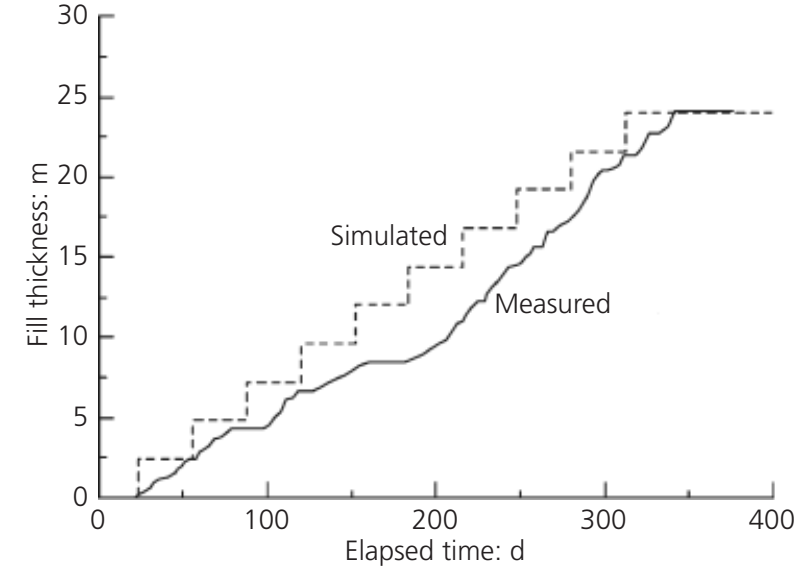

Figure 10. Embankment construction history

the stress state corresponding to the initial yielding condition (i.e. the maximum consolidation pressure). The listed over consolidation ratio (OCR) values were also back-estimated using the measured final compression of each soil layer, as well as referring to the values reported by Hirata et al. (2010). The undrained shear strength $\left(s_{\mathrm{u}}\right)$ was measured by an unconfined compression test using undisturbed soil samples.

The additional parameters required to estimate the consolidation of soils into which PVDs have been installed are listed in Table 2. Values of $D_{\mathrm{e}}$ were calculated from the PVD spacing and other parameters were assumed based on the recommendation of Chai and Miura (1999).

\subsubsection{Analysis}

The consolidation settlements were calculated assuming onedimensional (1D) deformation conditions under the embankment centreline. The unit weight of the embankment fill was assumed to be $18.6 \mathrm{kN} / \mathrm{m}^{3}$ (Hirata et al., 2010) and it was also assumed that the groundwater was located $0.5 \mathrm{~m}$ below the original ground surface. Although vacuum pressure was applied under the base of the embankment, given that the settlement was more than $10 \mathrm{~m}$, the buoyancy effect on the embankment fill (above the air-tight

\begin{tabular}{lccc}
\hline Parameters & Unit & $\begin{array}{c}\text { 0-20 m } \\
\text { depth }\end{array}$ & $\begin{array}{c}20-34 \mathrm{~m} \\
\text { depth }\end{array}$ \\
\hline Diameter of unit cell, $D_{\mathrm{e}}$ & $\mathrm{m}$ & 0.96 & 1.36 \\
Equivalent PVD diameter, $d_{\mathrm{w}}$ & $\mathrm{m}$ & 0.05 & 0.05 \\
Diameter of smear zone, $d_{\mathrm{s}}$ & $\mathrm{m}$ & 0.30 & 0.30 \\
Hydraulic conductivity ratio, $k_{\mathrm{h}} / \mathrm{k}_{\mathrm{s}}$ & - & 5 & 5 \\
Discharge capacity of PVD, $q_{\mathrm{w}}$ & $\mathrm{m}^{3} / \mathrm{d}$ & 0.274 & 0.274
\end{tabular}

Table 2. Additional parameters for PVD consolidation

sheet) could not be avoided. Assuming that about $10 \mathrm{~m}$ of the fill material was submerged, the maximum embankment load was estimated to be $348 \mathrm{kPa}$. The variation of the embankmentinduced loading with depth was approximated by Osterberg's method (Osterberg, 1957), as illustrated in Figure 11. As for the vacuum pressure, the measured excess pore water pressures at $7 \cdot 0$ and $17.0 \mathrm{~m}$ depths from the ground surface are depicted in Figure 12 (Kosaka et al., 2011). As the total embankment settlement was over $10.0 \mathrm{~m}$, the values of excess pore water pressure shown in Figure 12 were evaluated by carefully considering the effect of

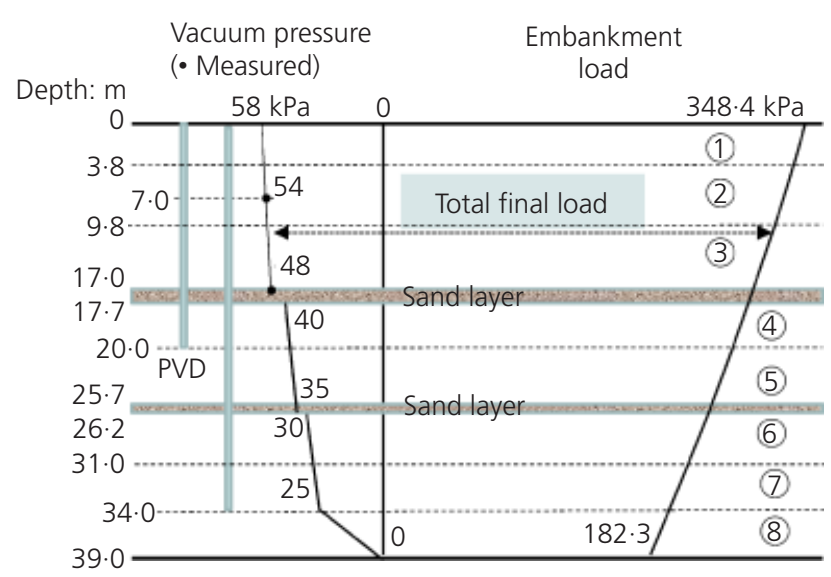

Figure 11. Estimated vacuum pressure and embankment load in the ground

\begin{tabular}{|c|c|c|c|c|c|c|c|c|}
\hline Soil layer & Thickness: m & $\begin{array}{c}\text { Unit weight: } \\
\gamma_{\mathrm{t}}: \mathrm{kN} / \mathrm{m}^{3}\end{array}$ & Void ratio $e_{0}$ & $\begin{array}{c}\text { Compression } \\
\text { index: } C_{c}\end{array}$ & OCR & $c_{h}: m^{2} /$ day & $c_{v}: m^{2} /$ day & $s_{u}: k P a$ \\
\hline Clay-1 & $3 \cdot 8$ & $13 \cdot 8$ & $3 \cdot 0$ & $1 \cdot 41$ & $2 \cdot 0$ & 0.018 & 0.009 & 10 \\
\hline Peat-1 & $6 \cdot 0$ & $14 \cdot 1$ & $2 \cdot 38$ & $1 \cdot 40$ & $1 \cdot 35$ & 0.048 & 0.024 & 30 \\
\hline Peat-2 & $7 \cdot 2$ & $13 \cdot 4$ & $3 \cdot 0$ & $1 \cdot 78$ & $1 \cdot 35$ & 0.076 & 0.038 & $19-52$ \\
\hline Sand-1 & $0 \cdot 7$ & $16 \cdot 3$ & $1 \cdot 5$ & - & - & & & \\
\hline Peat-3 & 8.0 & $14 \cdot 1$ & $2 \cdot 38$ & $2 \cdot 1$ & $1 \cdot 35$ & 0.084 & 0.042 & $29-40$ \\
\hline Sand-2 & 0.5 & $16 \cdot 3$ & $1 \cdot 5$ & - & - & & & \\
\hline Clay-2 & $4 \cdot 8$ & $16 \cdot 3$ & $1 \cdot 5$ & 0.33 & $1 \cdot 35$ & 0.200 & $0 \cdot 100$ & 50 \\
\hline Peat-4 & 8.0 & 11.9 & $5 \cdot 85$ & $4 \cdot 54$ & $2 \cdot 0$ & $0 \cdot 180$ & 0.090 & 82 \\
\hline
\end{tabular}

Table 1. Soil properties at Mukasa site 


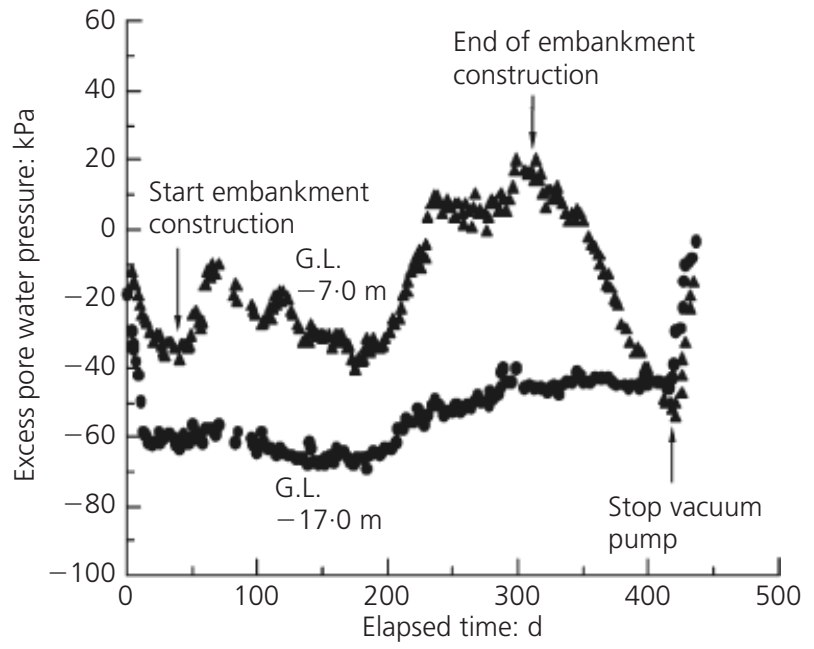

Figure 12. Measured excess pore pressure variations (date from Kosaka et al., 2011)

changes in the static water pressure induced by the large settlements. It can be seen that the vacuum pressure at the point which was originally at $17.0 \mathrm{~m}$ depth was higher than that at the point originally at $7.0 \mathrm{~m}$ depth, during most of the construction and consolidation period. The pore pressure gauge at $17.0 \mathrm{~m}$ depth was located at the interface between the peat- 2 and sand-1 layers (Figure 9), and it is considered that the vacuum pressure might have propagated to the gauge through the sand-1 layer, which had a higher hydraulic conductivity. However, it may be seen that just before vacuum pumping ceased, the vacuum pressure at the $7.0 \mathrm{~m}$ point was higher than at the $17.0 \mathrm{~m}$ point. Referring to the measured data at the time of stopping the vacuum pump, the estimated vacuum pressure distribution is as indicated in Figure 11. It is noted that during the whole process, a relatively higher vacuum pressure was maintained at the $17.0 \mathrm{~m}$ point, which implies that the sand layer was not a free drainage layer. Based on this consideration, only a small jump in the vacuum pressure was assumed below each sand layer in Figure 11.

In the consolidation analysis for layer (1) (Figure 11), both vertical and radial drainage effects were considered. For layer (8) only vertical drainage was considered using the method proposed by Ong et al. (2012), and for layers (2) to (7) only radial drainage was considered.

Terzaghi's 1D consolidation theory and Hansbo's solution (Hansbo, 1981) for PVD-induced consolidation are all for instantaneous loading. To consider the time-dependent embankment construction process, the following approximate method was adopted. The embankment construction was treated as stepwise loading in 10 equal steps (considering the effect of buoyancy, the vertical stress applied in each step was $38.4 \mathrm{kPa}$ ). The degree of consolidation and the compression for each loading step were calculated in the following manner. (i) Suppose at time $t_{i}$, the total applied load is $p_{i}$, and the degree of consolidation with respect to $p_{i}$ is $U_{i}$. A load increment $\Delta p_{j}$ is applied at the time, $t_{i}$, instantaneously, so that the degree of consolidation $\left(U_{j}\right)$ with respect to $p_{j}=p_{i}+\Delta p_{j}$ at time $t_{i}$ is

3. $U_{j}=\frac{U_{i} p_{i}}{p_{j}}$

(ii) With $U_{j}$ known, an imaginary time $t_{j 0}$ (or the time factor $T_{j 0}$ ) can be obtained from the corresponding consolidation theory.

(iii) At load $p_{j}$, time $t_{i}+\Delta t$, the degree of consolidation is calculated using a time of $t_{j 0}+\Delta t$.

Although the two sandy layers are not free drainage layers, it was assumed that their degree of consolidation is always $100 \%$, and the compression of these layers was computed using linear elasticity theory with a Young's modulus $(E)$ of $7000 \mathrm{kPa}$ and Poisson's ratio $(v)$ of $0 \cdot 3$.

\subsubsection{Comparison of calculated and the measured settlement curves}

The calculated and measured settlement-time curves are compared in Figure 13. It can be seen that generally the simple calculation resulted in a reasonable simulation of the measured results. At least one point is deserving of further explanation. The settlement of the ground surface was monitored before the sand mat was constructed, and at the time that the vacuum pressure was applied, the settlement of the ground surface was already about $1.0 \mathrm{~m}$ (Yamada et al., 2010). However, the subsurface settlements were only monitored from the time the vacuum pressure was applied. Therefore, the calculated subsurface settlements are larger than the corresponding measured values. As the construction history of the sand mat was not reported, in the

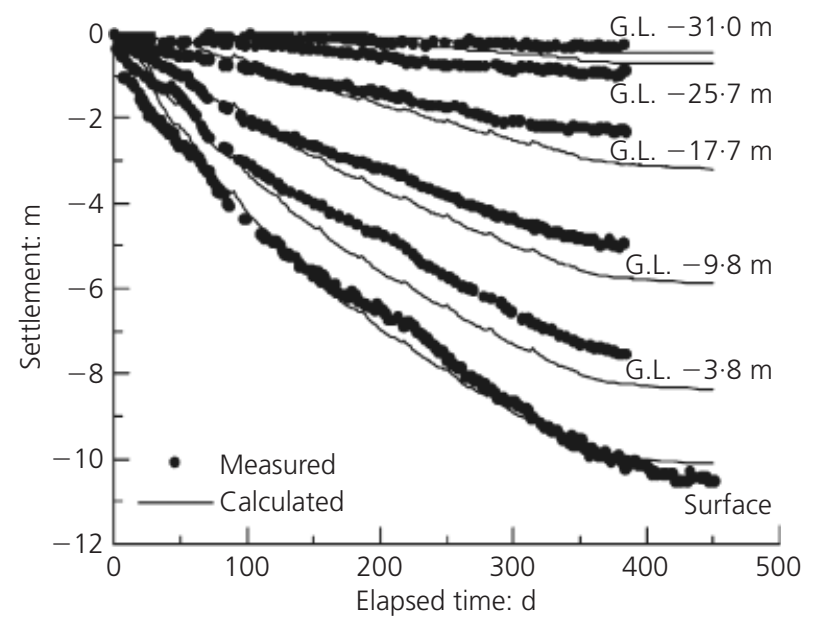

Figure 13. Comparison of settlement curves at Mukasa site 
analysis it was assumed that the sand mat should be included in the $24 \mathrm{~m}$ thick embankment fill.

\subsubsection{Measured lateral displacement}

The measured lateral displacement profiles are shown in Figure 14 (data from Minoru et al., 2010) for the sake of the completion of the information. Prior to the embankment construction, the inward lateral displacements were measured in the deposit with a maximum value of about $0.2 \mathrm{~m}$ occurring at the ground surface. In contrast, at the end of the embankment construction, the measured lateral displacements were outward with a maximum value of about $1.0 \mathrm{~m}$ occurring about $10 \mathrm{~m}$ below the ground surface. For a preloading project using a combination of vacuum pressure and embankment loading there is no well-established method for predicting the lateral displacement profile. Chai et al. (2013) proposed a semi-empirical method for predicting the possible range of maximum net lateral displacement $\left(\delta_{\mathrm{nm}}\right)$, where $\delta_{\mathrm{nm}}$ is defined as the maximum value of the net outward lateral displacement reduced by the maximum value of the net inward lateral displacement. The predicted range of $\delta_{\mathrm{nm}}$ corresponding to the end of embankment construction is included in Figure 14 also. It can be seen that the measured value is larger than the upper bound of the range. The maximum lateral displacement was observed at the elevation of the end of the sheet pile (Figure 9). It is therefore uncertain whether the bending movement of the sheet pile might have affected the observed maximum lateral displacement of the soil in this case. Also there is one layer of very soft peat at the ground surface, and the prediction method may not be suitable for this kind of situation (Chai et al., 2013), and further study of this aspect is needed.

\section{Concluding remarks}

There are two methods for conducting vacuum consolidation in the field, namely the air-tight sheet method and the vacuum-drain method. These two methods have their different advantages and disadvantages. For example, when consolidating a clayey deposit

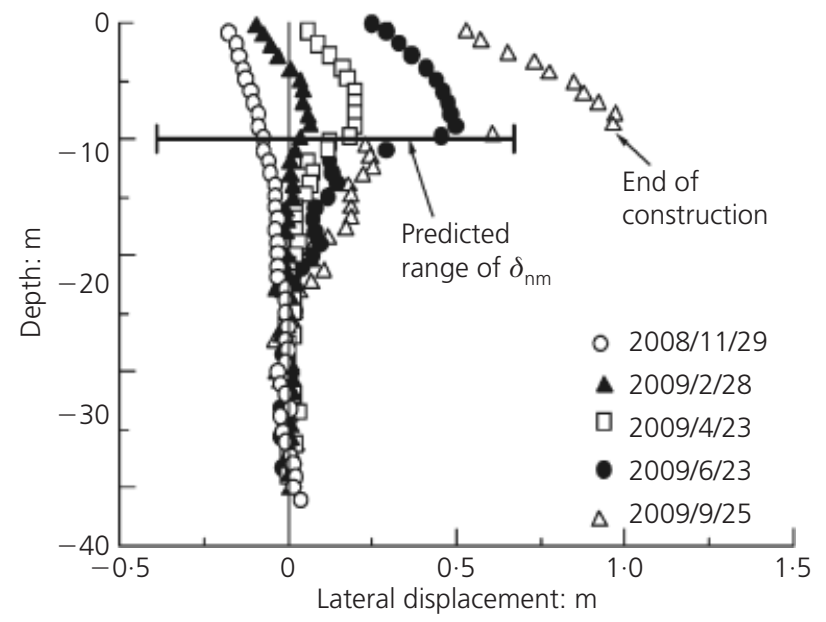

Figure 14. Measured lateral displacement profiles (date from Minoru et al., 2010) by applying a vacuum pressure under water, the vacuum-drain method has an advantage; whereas for the case of consolidating a soil layer at the ground surface using vacuum pressure, the airtight sheet method should usually be used.

There are sometimes soft deposits with a middle sand layer sandwiched in soft clay layers. In order to conduct vacuum consolidation for such a deposit while also preventing the vacuum leakage through the sand layer, a sealing sheet should be placed over the filter of those sections of PVDs passing through the sandy layer. In the case of the combination of an embankment load and a vacuum pressure, sometimes larger settlement can occur, and to prevent the vacuum pressure reduction due to relative settlement between the location of a vacuum pump and the improved area and to increase the efficiency of the pumping system, an air-water separation system may be used, in which a small pump for pumping out water is located in the improvement area, and a pump for pumping out air is located on the original ground surface.

Two typical field case histories in Japan have been described and deformation analyses have been conducted. One case history described a vacuum consolidation project conducted using the vacuum-drain method for a deposit under sea water, and the other was a preloading project with a combination of vacuum pressure and embankment loading employing the air-tight sheet method. It has been shown that under vacuum pressure, the ground deformation can be calculated quite well by the method proposed by Chai et al. (2005) plus the modification made in this study for an under-consolidated deposit. In cases involving a combination of vacuum pressure and embankment loading, the settlements under the embankment centreline can be reasonably calculated assuming 1D deformation conditions. However, for lateral displacement of the ground, especially when a very soft layer (such as a peat layer) exists at the ground surface, further research is needed to establish a reliable prediction method.

\section{Acknowledgement}

Partial support for this work was provided by the Australian Research Council, and Grants for Scientific Researches, Kajiam Foundation, Japan.

\section{REFERENCES}

Bergado DT, Chai JC, Miura N and Balasubramaniam AS (1998)

PVD improvement of soft Bangkok clay with combined vacuum and reduced sand embankment preloading. Geotechnical Engineering, Southeast Asian Geotechnical Society 29(1): 95-121.

Chai JC and Carter JP (2011) Deformation Analysis in Soft Ground Improvement. Springer, Dordrecht, the Netherlands. See http://dx.doi.org/10.1007/978-94-007-1721-3.

Chai JC and Miura N (1999) Investigation on some factors affecting vertical drain behavior. Journal of Geotechnical and Geoenvironmental Engineering, ASCE 125(3): 216-226.

Chai JC, Carter JP and Hayahsi S (2005) Ground deformation 
induced by vacuum consolidation. Journal of Geotechnical and Geoenvironmental Engineering, ASCE 131(12): 1552-1561.

Chai JC, Miura N and Bergado DT (2008) Preloading clayey deposit by vacuum pressure with cap-drain: Analyses versus performance. Geotextiles and Geomembranes 26(3): 220-230.

Chai JC, Hong ZS and Shen SL (2010) Vacuum-drain consolidation induced pressure distribution and ground deformation. Geotextiles and Geomembranes 28(6): 525-535.

Chai JC, Ong CY, Carter JP and Bergado DT (2013) Lateral displacement under combined vacuum pressure and embankment loading. Géotechnique 63(10): 842-856, http:// dx.doi.org/10.1680/geot.12.P.060.

Hansbo S (1981) Consolidation of fine-grained soils by prefabricated drains. Proceedings of the 10th International Conference on Soil Mechanics and Foundation Engineering, Stockholm, Sweden, vol. 3, pp. 677-682.

Hirata M, Kitoh M, Yamada K, lizuka A and Arai K (2010) Deformation behavior and counter measures of expressway embankment on super-soft ground. Journal of the Japan Society of Civil Engineers 66(2): 356-369 (in Japanese).

Imai G (2005) For the further development of vacuum-induced consolidation method - Present understandings of its principles and their applications. Proceedings of the Japanese Society of Civil Engineering 798/VI(68): 1-16 (in Japanese).

Indraratna B, Rujikiatkamjorn C, Ameratunga J and Boyle P (2011) Performance and prediction of vacuum combined surcharge consolidation at Port of Brisbane. Journal of Geotechnical and Geoenvironmental Engineering, ASCE 137(11): 1009-1018.

Kjellman W (1952) Consolidation of clayey soils by atmospheric pressure. Proceedings of the Conference on Soil Stabilization, Massachusetts Institute of Technology, USA, pp. 258-263.

Kosaka T, Kawaida M, Yamada K and Toyota M (2011) 10 meters of ground settlement behaviors induced by vacuum consolidation and high embankment highway construction. Proceedings of the 46th Annual Meeting of Japanese Geotechnical Society, Kobe, Japan, pp. 853-854 (in Japanese).

Minoru K, Kouichi Y and Kazuyoshi N (2010) Vacuum consolidation for construction of expressway embankment on extremely soft ground. Proceedings of the 9th Symposium on Ground Improvement, Japanese Society of Material, pp. 211216 (in Japanese).

Miyakoshi K, Takeya K, Otsuki Y et al. (2007a) The application of the vacuum compaction drain method to prolong the life of an offshore disposal field. Nippon Koei Technical Forum 16: 9-19 (in Japanese).

Miyakoshi K, Shinsha H and Nakagawa D (2007b) Vacuum consolidation field test for volume reduction scheme of soft clayey ground (Part-2) - ground characteristic and measured results. Proceedings of the 42th Annual Meeting, Japanese Geotechnical Society, pp. 919-920 (in Japanese).

Nakaoka J, Yoneya H, Nii K and Motonaga H (2005) Application of vacuum consolidation for improvement of soft ground reclaimed with dredged clayey soils: field conditions and measured results. Proceedings of the 40th Annual Conference of Japanese Geotechnical Society, Hakodate, Japan, pp. 1053-1054.

Nomura T, Yoshikawa M, Matuta Y and Miura N (2007) Case histories on using oil pressure as an index to judge the existence of sand layer. Journal of Foundation Construction 35(9): 88-92 (in Japanese).

Ong CY, Chai JC and Hino T (2012) Degree of consolidation of clayey deposit with partially penetrated vertical drains. Geotextiles and Geomembranes 34: 19-27. See http:// dx.doi.org/10.1016/j.geotexmem.2012.02.008.

Osterberg JO (1957) Influence values for vertical stresses in semi-infinite mass due to embankment loading. Proceedings of the 4th International Conference on Soil Mechanics and Foundation Engineering, London, UK, vol. 1, pp. 393-396.

Tang M and Shang JQ (2000) Vacuum preloading consolidation of Yaogiang Airport runway. Géotechnique 50(6): 613-623.

Terzaghi K (1943) Theoretical Soil Mechanics. Wiley, New York, USA.

Yamada K, Kawaita M, Shida J et al. (2010) A case history of combined vacuum pressure and embankment preloading on a very soft deposit. Proceedings of the 56th Annual Meeting of the Japanese Society of Civil Engineers, Tokyo, pp. 291-292 (in Japanese).

\section{WHAT DO YOU THINK?}

To discuss this paper, please email up to 500 words to the editor at journals@ice.org.uk. Your contribution will be forwarded to the author(s) for a reply and, if considered appropriate by the editorial panel, will be published as a discussion in a future issue of the journal.

Proceedings journals rely entirely on contributions sent in by civil engineering professionals, academics and students. Papers should be 2000-5000 words long (briefing papers should be 1000-2000 words long), with adequate illustrations and references. You can submit your paper online via www.icevirtuallibrary.com/content/journals, where you will also find detailed author guidelines. 